\title{
TIME SERIES ANALYSIS OF URBANISATION IMPACT ON THE TEMPERATURE VARIATIONS OFF MUMBAI COAST
}

\author{
Sutapa Bhattacharjee ${ }^{1 *}, \mathrm{~K}$. Lekshmi $^{1}$, R. Bharti ${ }^{1}$ \\ ${ }^{1}$ Department of Civil Engineering, Indian Institute of Technology Guwahati, Guwahati 39, Assam, India \\ sutapabhattacharjee22@gmail.com; lekshmik04@iitg.ac.in; rbharti@iitg.ac.in
}

KEY WORDS: SST, Urban Climate, Polynomial Regression, Harmonic Regression, ARIMA, NNAR.

\begin{abstract}
:
Urbanisation is an ever-evolving, complicated continuous process distinct from its surroundings, having the tendency to create a micro-scale system with characteristic local environmental conditions. Large-scale urbanization near the coasts has a definite impact on the coastal processes due to dynamic interactions of the coastal waters with the urban atmospheric, hydrological and anthropogenic residues. This study focuses on understanding the contribution of immediate atmospheric variations due to urbanization on surface temperature of coastal waters along the Mumbai coast. Different meteorological and air quality parameters such as Air Temperature (AT), Land Surface Temperature (LST), Precipitation (P), Relative Humidity (RH), Wind Speed (WS) and Aerosol Optical Depth (AOD) collectively were used as determinants of local urban climatic environment; to analyse and understand the impact of urbanization on Sea Surface Temperature (SST) representing coastal system. ERA5 Reanalysis meteorological data and MODIS satellite data products were used to extract information of the said parameters for a period of 20 years and time-series analysis was performed for each using Mann-Kendall method to establish their trend. Harmonic regression using Autoregressive Integrated Moving Average (ARIMA) and Neural Network Autoregression (NNAR) were used to model the existing and forecast the future trend of SST which showed an increasing trend with comparatively better representation by NNAR (RMSE $0.4-0.7$ K). Further, a polynomial multiple regression model was built to correlate the influence of all urban climatic parameters with SST, which clearly indicated positive forcing of local climate variation on the coastal waters with an $\mathrm{R}^{2}$ value of 0.93 .
\end{abstract}

\section{INTRODUCTION}

The ability of the sea to absorb atmospheric heat and gases alters and augments its different physical processes leading to a change in the entire system (Solomon et al., 2007). Although in micro-scale, these interactions and modifications are more prominent in the coastal region near large urban systems, which potentially aids in enhancing these processes (Riegel, 2002; Khan et al., 2005; Shearman and Lentz, 2009). Cities can be considered as one of the most complex spatial entities with constantly evolving dynamics, resulting in the expansion of their sphere of influence on the surrounding environment. Increase in the dimension and intensity of urbanization has the potential to modify various physical processes in the overlying atmosphere and environment enveloping it (Oke, 1976; Mills, 2007; Barlow, 2014). The coastal waters adjacent to the bigger metropolitan cities accommodating a huge magnitude of people and functions, undergo modifications in the surficial as well as sub-surface levels more prominently in comparison to that near non-urban areas (Riegel, 2002; Solomon et al., 2007). The significance of coastal regions is not only restricted to the landatmosphere-ocean interaction but also with respect to the quotient of primary productivity of the nutrient rich coastal waters (Falkowski et al., 2000).

Sea Surface Temperature (SST) is a very important parameter as it regulates the other physical, chemical as well as biological entities of the marine environment (Falkowski et al, 2000). Therefore, it is extremely necessary to understand the aggravated influence of the massive coastal cities on the temperature of the adjacent sea surface and sub-surface, which can further affect the other integrated processes. The local atmospheric conditions of a city experience an abrupt change from its surroundings due to increased surface as well as air temperature, and higher concentration of various gases and particulate matter trapped within. The interplay between the longwave radiations accentuated by the urban fabric and design, and the Green House Gases (GHGs) generated by the urban mechanisms lead to increase in air temperature in and around the cities resulting in the formation of Urban Heat Islands (UHIs) (Oke, 1976; Arnfield, 2003; Das et al., 2014). A microclimate zone is thus created within the Urban Boundary Layer with distinctive temperature, precipitation, humidity, wind patterns and GHG concentrations (Oke, 1976; Grimmond, 2005; Barlow, 2014).

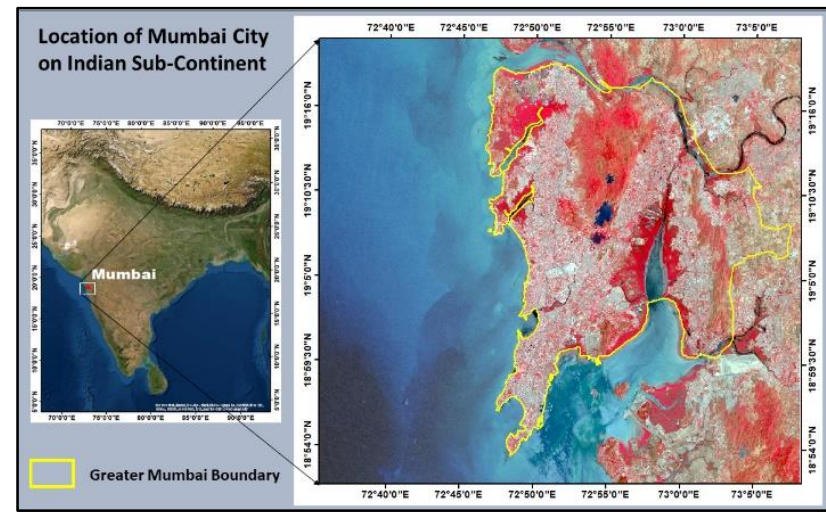

Figure 1. Study area

Mumbai is one of the largest and most important urban centres in India which is also considered as its commercial capital. The

\footnotetext{
* Corresponding author
} 
city lies on Arabian Sea coast extending from $18.9^{\circ} \mathrm{N}-19.3^{\circ} \mathrm{N}$ latitude to $72.78^{\circ} \mathrm{E}-73.06^{\circ} \mathrm{E}$ longitude (Figure 1). The city experiences coastal climate with almost moderate temperature, relatively high wind speed and humidity conditions throughout the year. The average annual temperature of the city is about $30^{\circ} \mathrm{C}$ which increases more than $36^{\circ} \mathrm{C}$ during the pre-monsoon months (March - May), considered to be the hottest. Mumbai lies in the most active south-west monsoon belt receiving heavy rainfall during the summer months (June -September), lowering the influence of heat and aerosol concentration to a certain extent on one hand but increasing the level of humidity on the other. Thus, the positive forcing of different surficial, meteorological and air quality parameters on temperature is distinct in case of Mumbai which has been increasing consistently with urban intensification since the past few decades (Kumar et al., 2001; Korade and Dhorde, 2016).

Time series analysis has been one of the key methods in analysing the behaviour of any natural or anthropogenic process persistent for a long period and can also contribute in establishing a future trend (Jain and Ormsbee, 2002; Korade and Dhorde, 2016; Mahmood et al., 2019). Univariate models such as ARIMA, NNAR, Wavelet Analysis etc have been widely used by researchers for predicting the trend of different meteorological parameters, on the basis of their long-term timeseries observation. These are typical harmonic regression models capable of considering the cyclic nature of the hourly, daily, monthly or seasonal time-series over a long period, for forecasting the future (Jain and Ormsbee, 2002; Tseng et al., 2002; Zhang, 2003; Ghiassia et al., 2005; Zhang and Qi, 2005; Faruk, 2010; Adamowski et al., 2012; Mahmood et al., 2019). ARIMA and NNAR models were therefore adopted to understand the prevailing trend in the observed SST values and also to generate the future scenario and validate the accuracy. However, the relationship of the coastal SST with that of the local climate of Mumbai city was ascertained by formulating a multiple polynomial regression model which is an efficient technique to understand the collective influence of different correlated or non-correlated variables on a dependent variable (Zaw and Naing, 2008; Zhu et al., 2009; Adamowski et al., 2012; George et al., 2016).

This study therefore attempts to understand the effect of urban growth and development on its immediate atmosphere, which is thereby transferred to the sea surface indicated by increase in the SST level in the urban coastal region. A spatio-temporal approach of investigation using various geospatial data and techniques have been adopted here to achieve an understanding of the nature and magnitude of influence of urbanization on the adjoining sea surface.

\section{METHODOLOGY}

SST is a function of various marine processes as well as the interaction between atmosphere and sea. This interaction increases in coastal region particularly adjacent to large urban centres as atmospheric processes intensifies, and also due to direct urban drainage discharge into the sea. However, this study focuses only on understanding the relationship between urban local climate on SST along the coastline of Mumbai. ERA5 reanalysis meteorological data $(25 \mathrm{~km}$ resolution) and MODIS satellite data $(1 \mathrm{~km})$ were used to analyse the trend of atmospheric, land surface and oceanic climate conditions over the city, its surroundings and the immediate coastal region; according to which the future scenario was predicted. Further a
Model was developed to understand the direct impact of variations in the urban climate on the nearby coastal waters (Figure 2).

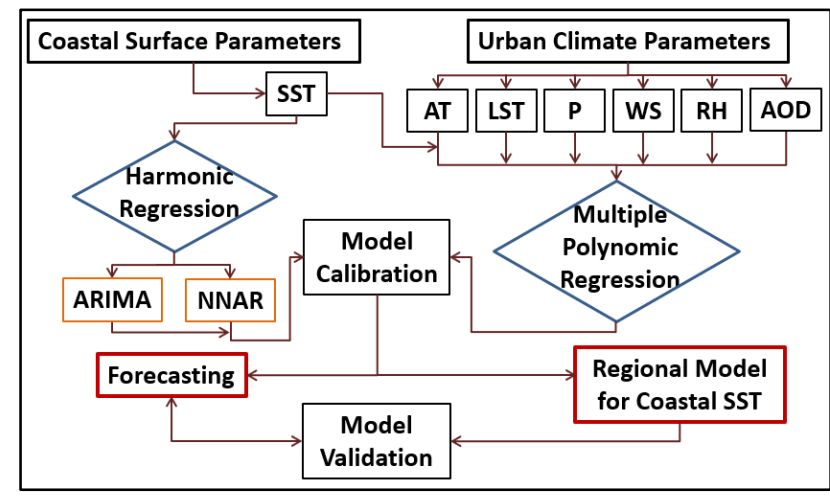

Figure 2. Methodology flow diagram

\subsection{Data Description}

The micro-climatic character of a city is governed by its meteorological and air-quality conditions induced by its complex surficial and functional characteristics. Therefore, to determine the local effect of urban dynamics on the coastal waters, few important meteorological and air quality parameters such as Air Temperature (AT), Land Surface Temperature (LST), Precipitation (P), Wind Speed (WS), Relative Humidity (RH) and Aerosol Optical Depth (AOD) were considered. These parameters together regulate the local climatic condition of a city and thereby the collective influence of urban climate on SST. ERA5 reanalysis gridded products provided by ECMWF are available with higher spatial and temporal resolution throughout the globe for most of the meteorological parameters and have been widely used for different global, regional as well as micro-scale climate studies (Cornes and Jones, 2013; Naseef and Kumar, 2019; Tarek et al., 2019; Gleixner et al., 2020). To maintain consistency between all the meteorological parameters pertaining to their pre-processing and resolution, ERA5 data was considered. These reanalysis meteorological data $(25 \mathrm{~km}$ resolution at $1000 \mathrm{mb}$ pressure level) products were extracted for variables such as AT, SST, RH, P, and WS. Besides, MODIS satellite data $(1 \mathrm{~km})$ was incorporated for the parameters LST and AOD due to their unavailability in ERA5, and was used after resampling to the resolution of remaining products (Figure 2, Table 1).

\begin{tabular}{|c|c|c|c|}
\hline Data & Source & Resolution & $\begin{array}{c}\text { Time- } \\
\text { Period }\end{array}$ \\
\hline SST & ECMWF - ERA5 & $25 \mathrm{~km}$ & $\begin{array}{c}\text { Jan. } 1990- \\
\text { Dec. 2020 }\end{array}$ \\
\hline AT & ECMWF - ERA5 & $25 \mathrm{~km}$ & $\begin{array}{c}\text { Jan. } 1990- \\
\text { Dec. 2020 }\end{array}$ \\
\hline LST & NASA - MODIS TERRA & $\begin{array}{c}1 \mathrm{~km} \text { (resampled } \\
\text { to } 25 \mathrm{~km})\end{array}$ & $\begin{array}{c}\text { Feb. 2000 - } \\
\text { Dec. } 2019\end{array}$ \\
\hline P & ECMWF - ERA5 & $25 \mathrm{~km}$ & $\begin{array}{c}\text { Jan. 2000 - } \\
\text { Dec. 2019 }\end{array}$ \\
\hline WS & ECMWF - ERA5 & $25 \mathrm{~km}$ & $\begin{array}{c}\text { Jan. } 2000- \\
\text { Dec. 2019 }\end{array}$ \\
\hline RH & ECMWF - ERA5 & $25 \mathrm{~km}$ & $\begin{array}{c}\text { Jan. } 2000- \\
\text { Dec. } 2019\end{array}$ \\
\hline AOD & NASA - MODIS TERRA & $\begin{array}{c}1 \mathrm{~km} \text { (resampled } \\
\text { to } 25 \mathrm{~km})\end{array}$ & $\begin{array}{c}\text { Feb. } 2000- \\
\text { Dec. 2019 }\end{array}$ \\
\hline
\end{tabular}

Table 1. Data used 


\subsection{Trend Analysis}

Mann-Kendall, a non-parametric method for trend identification in time series data was used to identify the significant trends in the input parameters. This method involves time-based ranking of data and treating each data point as a reference to compare with all data points which follow in time (Douglas et al., 2000; Mahmood et al., 2019). The statistical derivation of Man Kendal trend model (MKTM) can be given as Equation $1 \& 2$ :

$$
\begin{aligned}
& S=\sum_{i=1}^{n-1} \sum_{j=i+1}^{n} \operatorname{Sign}\left(T_{j}-T_{i}\right) \\
& \operatorname{Sign}\left(T_{j}-T_{i}\right)=\left\{\begin{array}{c}
1 \text { if } T_{j}-T_{i}>0 \\
0 \text { if } T_{j}-T_{i}=0 \\
-1 \text { if } T_{j}-T_{i}<0
\end{array}\right\}
\end{aligned}
$$

(Douglas et al., 2000; Rahman and Dawood, 2017)

\subsection{Time Series Analysis of SST}

SST data from 1990 to 2009 was used for harmonic regression analysis using Autoregressive Integrated Moving Average (ARIMA) and Neural Network Autoregression (NNAR) analysis which are the two important univariate regression models to analyse time-series data and forecast using historic trends. The trend of SST was first modelled using 20-years time-series (1990 - 2009) applying both ARIMA and NNAR methods, which was further validated using 10-year data (2010 - 2019). The entire 30-year period $(1990$ - 2019) was then implemented to predict SST trend till the year 2040.

2.3.1 ARIMA Model: This model is capable of identifying complex patterns in univariate time series data to generate forecasts. The ARIMA model development includes three steps namely, identification, estimation and forecasting. Model identification step involves two stages; first is achieving static and normalized time series data input through appropriate differencing followed by the second stage of analyzing autocorrelation and partial autocorrelation of the transformed data to find the temporal correlation structure. Once the model functions are identified, parameters for these functions are to be estimated and model residuals to be examined through several diagnostic tests for model verification (Tseng et al., 2002; Zhang, 2003; Faruk, 2010; Adamowski et al., 2012). ARIMA model can be represented as Equation 3,

$\Phi p(B)(I-B) d Y t=\delta+\theta q(B) \varepsilon t$

where $\mathrm{Yt}$ is the original time series value, $\Phi p$ is the autoregressive parameter of order $p$, $\varepsilon$ t is white noise, B is backshift operator, $\mathrm{d}$ is the differentiation order, $\delta$ is a constant value and $\theta p$ is the moving average parameter of order $q$ (Adamowski et al., 2012).

2.3.2 NNAR Model: It is a feed-forward neural network fitted with lagged time series values as input and a single hidden layer. The major advantages of Neural Network model over other methods are that apriori knowledge is not required for its application and it is effective in dealing with non-linear data sets (Faruk, 2010; Adamowski et al., 2012). A three-layer feedforward neural network can be given as Equation 4,

$O_{k}=g_{2}\left[\sum_{j} V_{j} w_{k j} G_{1}\left(\sum_{i} w_{j i} I_{i}+w_{j o}\right)+w_{k o}\right]$ where Ii is input value to node $\mathrm{I}, \mathrm{Vj}$ is the hidden value to node $\mathrm{j}$ of the hidden layer and $\mathrm{Ok}$ is the output at node $\mathrm{k}$ of the output layer (Adamowski et al., 2012).

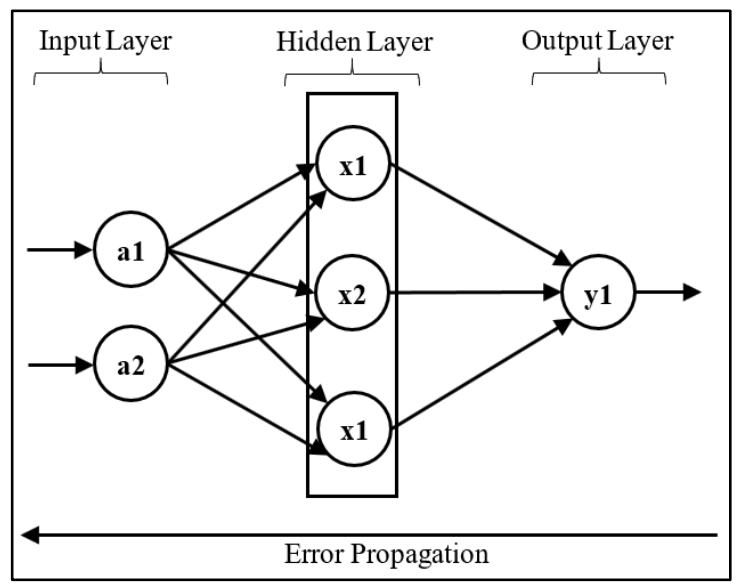

Figure 3. A three-layer feed-forward back-propagation neural network (Source: after Jain and Ormsbee, 2002)

Back-propagation neural network is the most commonly used model structure Figure 3. The circles represent neurons and lines represent connections; a layer consists of a group of neurons with similar characteristics. Here, Figure 3 consists of a two-neuron input layer, three-neuron hidden layer and a singleneuron output layer. The input given is propagated in the forward direction and using a nonlinear function output is calculated. This step is followed by computation of error at the output layer, back-propagation of the error through the network and updation of the weights using a nonlinear optimisation function. This whole process of neural network training is repeated to minimize the error and the well-trained neural network model is then used for prediction (Jain and Ormsbee, 2002; Tseng et al., 2002; Zhang, 2003; Ghiassia et al., 2005; Zhang and Qi, 2005).

To understand the cyclic nature in the time-series sufficiently and predict its future trend accommodating this typical behaviour, the results from both these harmonic regression models were compared and validated. Further, pre-monsoon season SST for the entire period, which records highest temperature annually was analysed for variations in maximum temperature.

\subsection{Modelling SST Using Local Climate Variables}

Time series data of monthly LST and AOD from MODIS, and AT, WS, P and RH from ERA5 were used to statistically analyse and model the impact of urbanization on the SST trends over a period of 17 years from 2000 to 2017 using multiple polynomial regression, and 2-year data from 2018 to 2019 was used to validate the model. The time - period for developing and validating the model was restricted to 20 years due to the unavailability of LST and AOD products beyond the year 2000.

\section{ANALYSIS AND RESULTS}

\subsection{Trend Analysis}

It was observed from trend analysis that air temperature over the city has increased significantly in the said period, the maximum 
temperature during 1990 being $303 \mathrm{~K}$ which increased to around $309 \mathrm{~K}$ in 2020 . There has been about 50 percent increase in the number of days with high temperature $(>302 \mathrm{~K})$ from 1990 to 2020. Annual average air temperature over the sea surface has also exhibited an increase of around $1 \mathrm{~K}$ for the period 1990 to 2020 from the coastal region $\left(72.75^{\circ} \mathrm{E}\right.$ Longitude) towards the open ocean $\left(72.0^{\circ} \mathrm{E}\right.$ Longitude) (Figure. 2 ). It showed a gradually increasing trend through 2010 , which however declined by around $0.5 \mathrm{~K}$ in 2020 , due to a remarkable decrease in the urban function during the Covid-19 pandemic lockdown enforced in India. Similarly, SST also showed an increasing trend over the period 1990 to 2010 with a rise of about $1 \mathrm{~K}$, and falling by around $0.3 \mathrm{~K}$ in 2020 as compared to 2010 (Figure. 4). Thus, due to the abnormal atmospheric conditions pertaining to the Covid-19 lockdown situation, the year 2020 was not considered in the study period, which was restricted 2019. Then Mann-Kendall test performed for SST and AT time-series in the 30-year period showed p-values of 0.022 and 0.036 respectively which depicts strong to very strong trend in the data.

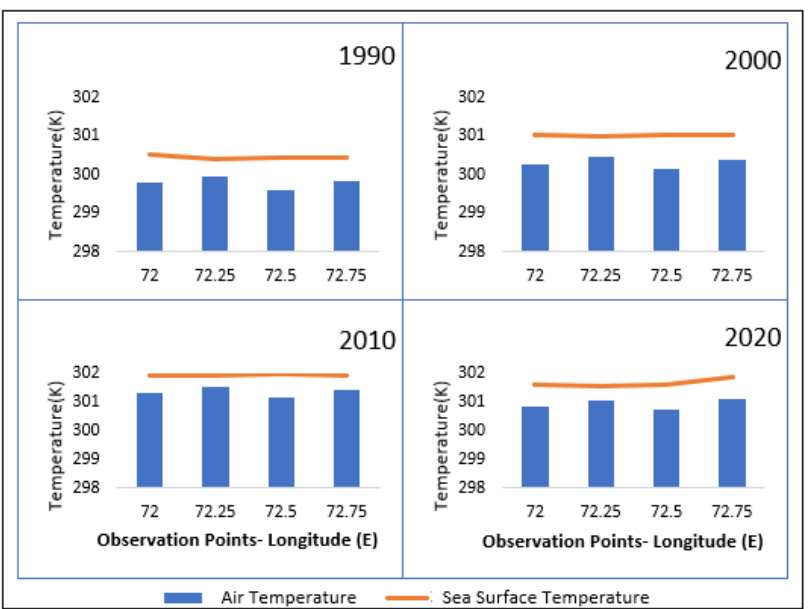

Figure 4. Annual average AT vs Annual average SST (19902020)

\subsection{Time Series Analysis of SST}

Analysis of time series SST data using ARIMA and NNAR models for 30 years showed a better representation of SST trends by the neural network.

3.2.1 Model Calibration and Validation for ARIMA and NNAR: Validation results provided RMSE values in the range 0.4 to 0.7 Kelvin for NNAR model while for ARIMA model, the RMSE values ranged from 0.6 to 1 Kelvin. Correlation analysis between the observed and predicted SST values also provided better results in NNAR model with 0.86 coefficient of determination (Figure 5).

3.2.2 Forecasting SST using ARIMA and NNAR Models: Forecast results showed a better representation of the observed data trend in NNAR model output as compared to ARIMA model output (Jain and Ormsbee, 2002). SST trends derived from the 30-year observational data showed monthly maximum temperature values $(303.5 \mathrm{~K})$ in pre-monsoon season and minimum values $(297 \mathrm{~K})$ in winter. NNAR forecast results provided monthly maximum temperature values reaching up to
$303.3 \mathrm{~K}$ in pre-monsoon season and minimum in winter as low as 298K. ARIMA results showed an overestimation of maximum values, with a highest temperature value of $306 \mathrm{~K}$ during monsoon season while underestimating the minimum temperature values with a lowest value of $295 \mathrm{~K}$ in winter (Figure 6,7).

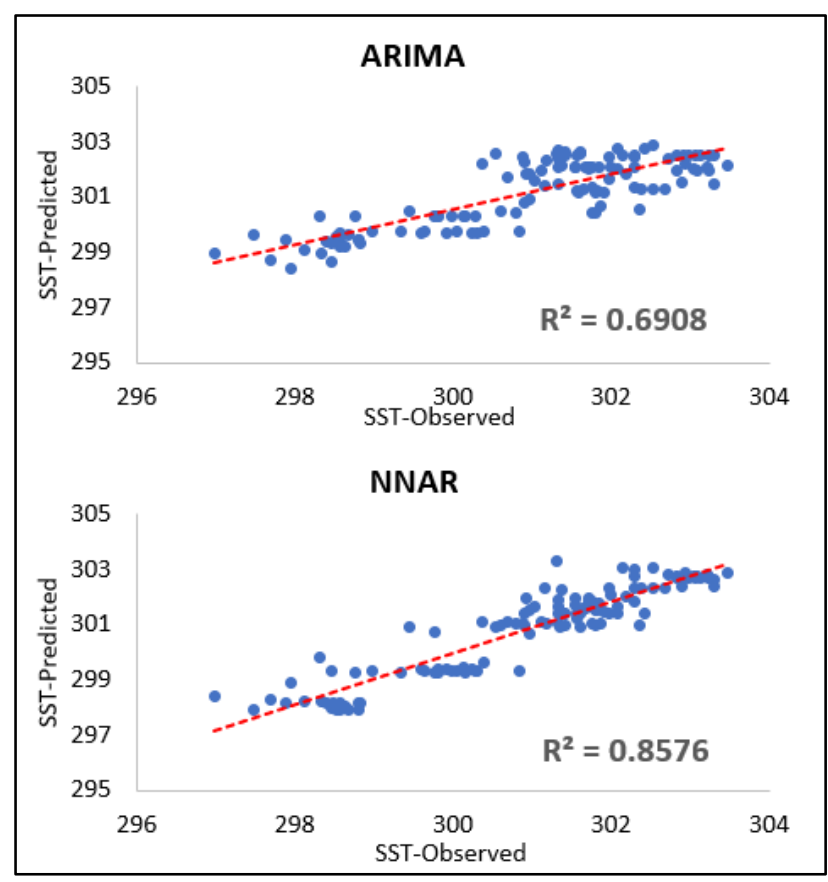

Figure 5. ARIMA \& NNAR model validation

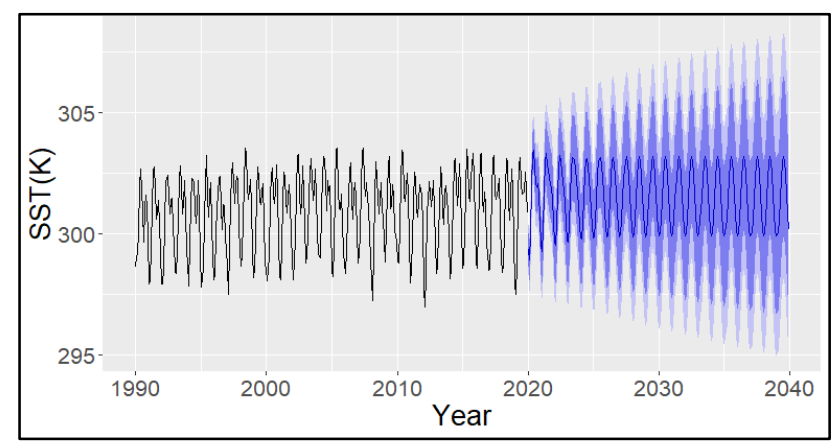

Figure 6. SST forecast using ARIMA for the period 2020 to 2040

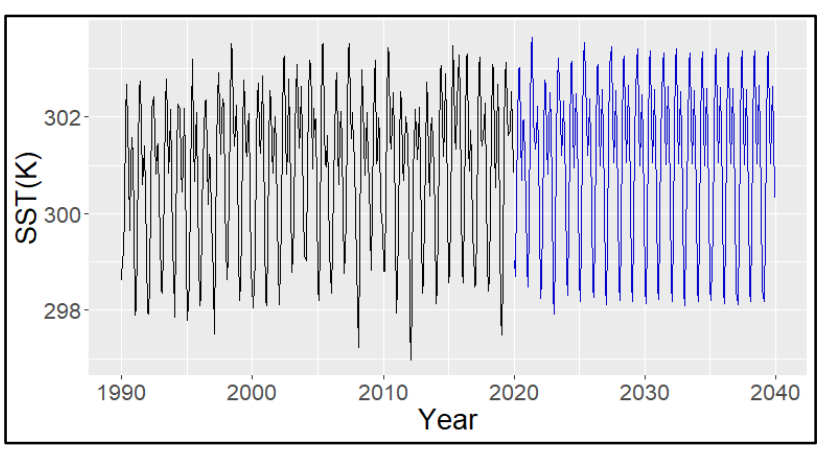

Figure 7. SST forecast using NNAR for the period 2020 to 2040 
SST values during pre-monsoon season for the observational data from 1990 to 2019 and the predicted data from 2020 to 2040 was plotted to understand the trends in maximum temperature values, which exhibited an increasing trend over the period (Figure 8).

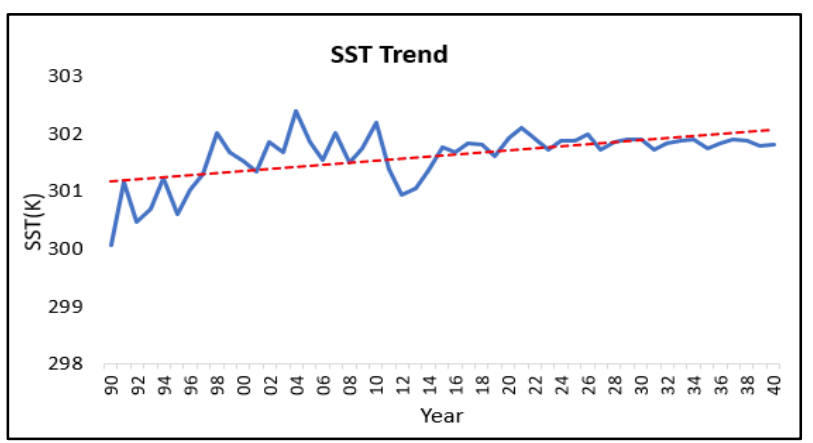

Figure 8. Trend in SST for the period 1990 to 2040

\subsection{Coastal SST Modelling}

3.3.1 Model Development and Calibration: Multiple regression analysis carried out to establish the impact of variations in AT, LST, AOD, RH, WS and P on the coastal SST of Mumbai city showed that SST trends are considerably affected by the local climate variables. While a good correlation with coefficient of determination value of 0.86 was obtained for linear regression analysis (Equation 5), the model was further improved using polynomial regression model of order 2 (Equation 6) which provided a coefficient of determination value of 0.93 . The regression models can be given as,

$$
\begin{aligned}
& \mathrm{SST}=56.74-0.034 \mathrm{AT}+0.83 \mathrm{LST}-0.19 \mathrm{AOD}- \\
& 0.01 \mathrm{WS}+0.07 \mathrm{RH}-0.0002 \mathrm{P}
\end{aligned}
$$

$$
\begin{aligned}
& S S T=4673-1.57 A T-27.3 L S T-2.51 A O D- \\
& 21.8 W S-2.82 R H-4.77 P+0.0108 A T 2+ \\
& 0.0568 L S T 2+0.541 A O D 2+0.0262 W S 2+ \\
& 0.00128 R H 2+0.000921 P 2-0.0198 A T \times \\
& L S T-0.363 \times A T \times A O D+0.00965 \times A T \times \\
& W S+0.0136 \times A T \times R H-0.00427 \times A T \times \\
& P+0.389 \times L S T \times A O D+0.0612 \times L S T \times \\
& W S-0.00485 \times L S T \times R H+0.0201 \times L S T \times \\
& P-0.0207 \times A O D \times W S-0.0569 \times A O D \times \\
& R H+0.019 \times A O D \times P+0.00468 \times W S \times
\end{aligned}
$$

3.3.2 Model Validation: Validation of the model using 2-year monthly data from 2018 to 2019 has given a root mean square error (RMSE) value in the range 0.1 to 0.5 Kelvin. Modelled SST values showed a good agreement with the observed SST values with a coefficient of determination value of 0.9 (Figure 9).

\section{DISCUSSION AND CONCLUSION}

Mumbai is one of the most populous and dynamic coastal cities in Indian sub-continent as well as the world. Its strategic location on the Arabian Sea coast and resource availability has earned it the status of commercial and industrial capital as well political significance. However, the extensive and rapid growth of the city has taken a definite toll on the local environmental conditions including on the coastal surface. This study specifically discusses the variations in SST over a period of 30years along the coastline of Mumbai and its relationship with that of the evolving urban meteorological and air quality conditions resulting from expulsive urban development. It was observed through the analysis that SST off Mumbai coast has inclined significantly during the said period $(1990-2019)$ to about $2 \mathrm{~K}$, in comparison to the open ocean along the same latitude beyond the coast. This implies the impact of the city on the coastal waters which has the potential to reverse-influence the city's climate including AT, WS and wind directions, moisture content in the atmosphere, local convective rains etc. Therefore, forecasting of SST on the basis of the past and current trends was adopted to understand and predict future scenario for 20-years beyond present, using ARIMA and NNAR autoregression models. It was found that both models well identified the data patterns and represented the SST trends to generate fairly good forecast values, in which NNAR model found to provide comparatively better results with a low RMSE value in the range 0.4 to $0.7 \mathrm{~K}$.

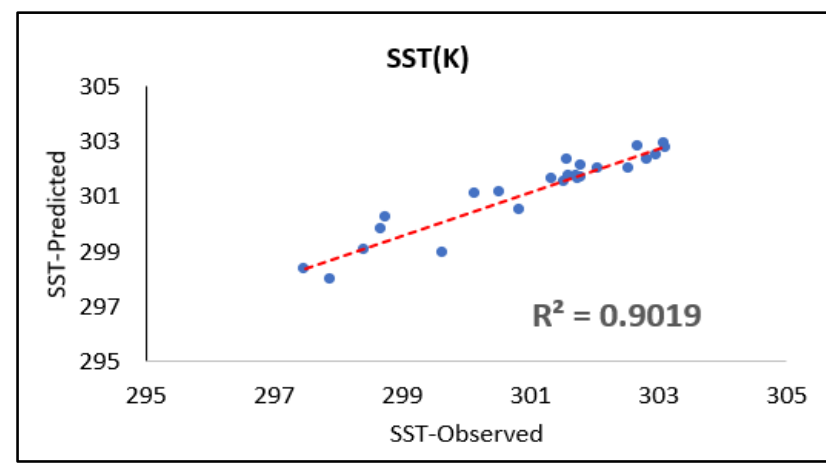

Figure 9. SST model validation

Although SST is a function of many other factors, only localised variations in climatic parameters within the urban boundary layer of Mumbai were considered in this study as the major factors affecting its change near the city's coastline. To understand the magnitude of Mumbai's local climatic influence on this SST variations, different parameters such as AT, LST, P, RH, WS and AOD were considered to build a polynomial regression model. This regional algorithm thus developed could be used to understand the contribution of said variables on the coastal surface temperature using such data products. Further the model can be used for predicting SST according to the availability of all urban climatic variables together, as opposed to the above-mentioned univariate prediction model. Further the model could be used to downscale SST values using longer time-series and higher resolution data products, incorporating the detailed urban mechanisms and corresponding intra-city micro-scale variations on the adjacent coastal environment. The methodology could be easily replicated for other regions or using other data products which could establish the merit of the study.

\section{ACKNOWLEDGEMENT}

The authors would like to thank all the data providers including ECMWF and NASA for making crucial high resolution meteorological and air quality data freely available for academic purposes. The authors are also grateful to Indian Institute of 
Technology Guwahati, specifically Dept of Civil Engineering for providing necessary infrastructure for successful completion of this research.

\section{REFERENCES}

Adamowski, J., Chan, H.F., Prasher, S.O., Zielinski, B.O., Sliusarieva, A., 2012: Comparison of multiple linear and nonlinear regression, autoregressive integrated moving average, artificial neural network, and wavelet artificial neural network methods for water demand forecasting in Montreal, Canada. Water Resources Research, 48: 1-14, W01528. doi:10.1029/2010WR009945.

Arnfield, A.J., 2003: Two decades of Urban Climate Research: A Review of Turbulence, Exchanges of Energy and Water, and the Urban Heat Island. International Journal of Climatology 23:1-26.

Barlow, J.F., 2014: Progress in observing and modelling the urban boundary layer. Urban Climate, 10:216-240. http://dx.doi.org/10.1016/j.uclim.2014.03.011.

Cornes, R.C., Jones, P.D., 2013: How well does the ERAInterim reanalysis replicate trendsin extremes of surface temperature across Europe?. Journal of Geophysical Research: Atmospheres, 118:10,262-10,276. doi:10.1002/jgrd.5079.

Das, Y., Padmanabhamurty, B., Murty, A.S.N., 2014: Some Parameterizations of Radiative Fluxes at Atmospheric Boundary Layer (ABL). Journal of Atmospheric Pollution, 2(1):1-5.

Douglas, E.M., Vogel, R.M., Kroll, C.N., 2000: Trends in floods and low flows in the United States: impact of spatial correlation. Journal of Hydrology, 240:90-105.

Falkowski, P., Scholes, R.J., Boyle, E., Canadell, J., Canfield, D., Elser, J., Gruber, N., Hibbard, K., Hogberg, P., Linder, S. Mackenzie, F.T., Moore III, B., Pedersen, T., Rosenthal, Y., Seitzinger, S., Smetacek, V., Steffen, W., 2000: The Global Carbon Cycle: A Test of Our Knowledge of Earth as a System. Science, New Series, 290(5490):291-296.

Faruk, D.O., 2010: A hybrid neural network and ARIMA model for water quality time series prediction. Engineering Applications of Artificial Intelligence, 23:586-594.

George, J., Janaki, L., Gomathy, P.J., 2016: Statistical Downscaling Using Local Polynomial Regression for Rainfall Predictions - A Case Study. Water Resource Management, 30: 183-193. https://doi.org/10.1007/s11269-015-1154-0.

Ghiassia, M., Saidaneb, H., Zimbra, D.K., 2005: A dynamic artificial neural network model for forecasting time series events. International Journal of Forecasting, 21(2): 341-362.

Gleixner, S., Demissie, T., Diro, G.T., 2020: Did ERA5 Improve Temperature and Precipitation Reanalysis over East Africa?. Atmosphere, 11:996. doi:10.3390/atmos11090996.

Grimmond, C.S.B., 2005: Progress in measuring and observing the urban atmosphere. Theoretical and Applied Climatology, 84(1-3):3-22. http://dx.doi.org/10.1007/s00704-005-0140-5.
Jain, A., Ormsbee, L., 2002: Short-term water demand forecast modeling techniques: Conventional methods versus AI. Journal of American Water Works Association, 94(7): 64-72.

Khan, T.M.A. Quadir, B.A., Murty, T.S. \& Sarker, M.A. 2004: Seasonal and interannual sea surface temperature variability in the coastal cities of Arabian Sea and Bay of Bengal. Natural Hazards, 31:549-560.

Korade, M., Dhorde, A., 2016: Trends in surface temperature variability over Mumbai and Ratnagiri cities of coastal Maharashtra, India. Mausam, 67(2):455-462.

Kumar, S., Prasad, T., Sasidharan, N.V., Nair, S., 2001: Heat Island intensities over Brihan Mumbai on a cold winter and hot summer night. Mausam, 52:703-708. CrossRef

Mahmood, R., Jia, S., Zhu, W., 2019: Analysis of climate variability, trends, and prediction in the most active parts of the Lake Chad basin, Africa. Scientific Reports, 9:6317. https://doi.org/10.1038/s41598-019-42811-9.

Mills, G., 2007: Cities as agents of global change. International Journal of Climatology, 27:1849-1857.

Naseef, M.T., Kumar, V.S., 2019: Climatology and trends of the Indian Ocean surface waves based on 39-year long ERA5 reanalysis data. International Journal of Climatology. https://doi.org/10.1002/joc.6251.

Oke, T.R., 1976: The distinction between canopy and boundarylayer heat islands. Atmosphere, 14:268-277.

Rahman, A., Dawood, M., 2017: Spatio statistical analysis of temperature fluctuation using Mann- Kendall and Sen's slope approach. Climate Dynamics, 48:783-797. 10.1007/s00382016-3110-y.

Riegel, B., 2002: Effects of the 1996 and 1998 positive seasurface temperature anomalies on corals, coral diseases and fish in the Arabian Gulf (Dubai, UAE). Marine Biology, 140:29-40.

Shearman, R.K., Lentz, S.J., 2009: Long-Term Sea Surface Temperature Variability along the U.S. East Coast. Journal of Physical Oceanography, 40:1004-1016.

Solomon, S., Qin, D., Manning, M., Chen, Z., Marquis, M., Averyt, K.B., Tignor, M., Miller, H.L., 2007: Contribution of Working Group to the Fourth Assessment Report of the Intergovernmental Panel on Climate Change. Cambridge University Press, Cambridge, United Kingdom and New York, NY, USA

Tarek, M., Brissette, F.P., Arsenault, R., 2019: Evaluation of the ERA5 reanalysis as a potential reference dataset for hydrological modeling over North-America. Hydrology and Earth System Sciences. https://doi.org/10.5194/hess-2019-316.

Tseng, F., Yu, H., Tzeng, G., 2002: Combining neural network model with seasonal time series ARIMA model. Technological Forecasting and Social Change, 69(1): 71-87. https://doi.org/10.1016/S0040-1625(00)00113-X.

Zaw, W.T., Naing, T.T., 2008: Empirical Statistical Modeling of Rainfall Prediction over Myanmar. International Journal of Computer and Information Engineering, 2(10): 3418-3421. 
Zhang, G.P., 2003: Time series forecasting using a hybrid ARIMA and neural network model. Neurocomputing, 50:159175. https://doi.org/10.1016/S0925-2312(01)00702-0.

Zhang, G.P., Qi, M., 2005: Neural network forecasting for seasonal and trend time series. European Journal of Operational Research, 160(2): 501-514.

Zhu, Y., Shag, S., Zhai, W., Dai, M., 2009: Satellite-derived surface water $\mathrm{pCO}_{2}$ and air-sea $\mathrm{CO}_{2}$ fluxes in the northern South China Sea in Summer. Progress in Natural Science, 19:775-779. 